\title{
Ruptly: em busca de um protagonismo no mercado dominado pelas agências do Ocidente
}

\section{Maria Cleidejane Esperidião'}

\section{Resumo}

Este artigo é um esforço interpretativo para analisar a agência de notícias russa Ruptly, que começou a operar em 2013. Contextualizamos o papel dela como um novo ator na irrigação atual do sistema noticioso do telejornalismo mundial, desafiando agências ocidentais como Reuters TV e Associated Press Television News (APTN). Usamos como estratégia de pesquisa o levantamento de dados e a revisão de literatura. Três fatores podem ter contribuído para seu crescimento: a emergência da narrativa russa de se contrapor à hegemonia europeia e americana; a transição das agências no modo de disseminar seus conteúdos para clientes que atuam não apenas como emissoras, mas, como veículos multiplataforma integrados; e ao esgotamento do modelo de negócios.

Palavras-chave: Agências de notícias. Ruptly. Jornalismo internacional.

\section{Abstract}

This paper seeks to discuss the arrival of the Russian news agency Ruptly, launched in 2003. Nevertheless, is an attempt to contextualize its role as a new player within the global news ecosystem, challenging the duopoly of two giants: Reuters TV and Associated Press Television News (APTN). The paper is based on data collection and literature review. This article claims that the rise of Ruptly was mainly due to three factors: the emergence of the Russian narrative as an alternative and opposition to European and American hegemony; to the transition of agencies in the way they disseminate their output/content to clients, not only broadcasting stations but multiplatform media outlets; and to the erosion of a business model drafted over a media environment that partially tore those rules.

Keywords: News agencies. Ruptly. International Journalism.

\footnotetext{
1 Jornalista e editora internacional. Cobriu os principais temas destacados pela mídia global desde 2006.Tem Doutorado em Comunicação Social pela Universidade Metodista de São Paulo, com ênfase nas agências de notícias internacionais. Estuda notícias internacionais desde 1996, quando fez mestrado em Jornalismo na escola de jornalismo da Cardiff University, na Inglaterra. Foi bolsista do Reuters Institute for the Study of Journalism, em Oxford, na Inglaterra. E-mail: mariacleidejane@hotmail.com.
}

Revista Pauta Geral-Estudos em Jornalismo, Ponta Grossa, vol. 6, n. 1, p. 78-94, Jan/Jun, 2019. 


\section{Introdução}

A escassez de estudos e o ainda tímido interesse sobre agências de notícias nas universidades brasileiras por si só já justificaria uma atenção específica àquelas que dominam o escoamento de imagens para canais de televisão do mundo. Décadas se seguiram nas escolas de comunicação com uma produção pífia do reconhecimento dessas empresas, que herdaram o legado de suas "marcas", gestado na metade do século 19 (SILVA JR; ESPERIDIÃO; AGUIAR, 2014). A partir dos anos 1960, elas se tornaram atores-chave na globalização. Portanto, essa desproporcionalidade diante do gigantismo discursivo das agências e suas influências nas narrativas do jornalismo mundial é um resgate necessário. Agências vendem e distribuem muito mais que notícias. Negociam, na verdade, uma "garantia de cobertura" e, principalmente, uma visão do que merece ser "notícia" no mundo (ESPERIDIÃO, 2011).

O conteúdo vendido pelas agências é postulado pelas empresas como crível, abrangente e de diversos temários. Mas os despachos fornecidos por elas têm sido objeto de crítica, mais intensamente a partir da década de 1970, quando a Unesco sistematizou esses questionamentos e propôs inseri-los dentro da Nova Ordem de Comunicação Mundial, a Nomic. Um dos pontos centrais daquele debate era o alinhamento das agências com interesses políticos e econômicos das superpotências em detrimento do "eixo-sul" do planeta (países pobres e em desenvolvimento), que acabava se refletindo nos seus informes. Uma acusação sempre relativizada e negada pelas agências. Intentase aqui descrever como um novo nome de serviço noticioso se comporta: a agência russa Ruptly, criada a partir de abril de 2013.

\section{Inventário histórico das agências e o asset da neutralidade}

Associated Press e Reuters resistiram em operar transmissões de imagem e áudio que até o final da década de 1980 se constituíam em operações caríssimas e pouco rentáveis. Nos anos 1960, os satélites de comunicação já haviam provocado uma revolução para as agências de escopo similar ao daquela causada pelo telégrafo, um século antes. Todavia, só a partir dos anos 1990 concretizou-se o que Manuel Castells (2005) caracteriza como a globalização econômica completa, ligando, em tempo real, centros financeiros e administrativos e articulando, em níveis nunca antes vistos, a convergência entre a tecnologia, a informática e as telecomunicações. Foi assim que a Associated Press Television News e a Reuters Television, que carregaram o prestígio de 2019. 
suas "marcas-mãe" e se estabeleceram por meio de parcerias cruciais com as emissoras americanas e britânicas.

A Visnews, sediada em Londres, foi oficialmente a primeira agência telejornalística e surgiu em 1964, ainda encorajada pelo modelo semicomercial de distribuição de imagens e áudio operado desde a Segunda Guerra Mundial pelo então The British and Commonwealth International Newsfilm Agency, o BCINA (PATERSON, 2011). Era controlada inicialmente pela emissora pública britânica British Broadcasting Corporation (BBC) e pela Reuters, sendo o restante do capital dividido entre uma série de serviços públicos de informação de ex-colônias britânicas, como o Australian Board Corporation. No entanto, para enfrentar a concorrência nesse terreno fértil de possibilidades comerciais via satélite, foi preciso se associar à National Broadcasting Company, a NBC, pioneira na radiodifusão americana, que, aos poucos, foi comprando o espólio dos outros acionistas minoritários.

Dez anos depois de formada, a Visnews já havia arregimentado 160 emissoras como assinantes, contratado 24 cinegrafistas e reunido 400 colaboradores, além de prover os clientes com novos serviços, como a cessão de fotos e filmes datados desde 1896, a terceirização de equipamentos e o fornecimento de pessoal (TORNEY-PARLICKI, 2000). Além da BBC, a Independent Television News (ITN) associou-se em 1967 à UPI para disputar o mercado, especialmente nas suas zonas de influência mais definidas: Estados Unidos e América Latina. A UPI já acumulava alguma experiência na empreitada: desde 1935 vendia boletins em vários idiomas para emissoras de rádio e era parceira da Fox Movietone/20th Century Fox, dissipando imagens para cadeias de cinema e televisão nos Estados Unidos e na Europa. Soberanas no segmento comercial, ainda que não exclusivas no intercâmbio entre emissoras, a Visnews e a UPITN repartiram a alimentação de informes televisivos durante a década de 1970, com o nascimento em cascata de emissoras nos países subdesenvolvidos. Essas empresas assinavam contratos para viabilizar a abertura de sucursais no exterior, pois os grandes eventos do dia seriam, enfim, relatados por seus correspondentes, usando basicamente o farto material de agência.

Em 1985, depois de anos registrando prejuízos que contaminaram as outras divisões da UPI (texto e foto), a UPITN foi adquirida pela Worldwide Television News (WTN), da Capital Cities Corp, e pela rede America Broadcasting Company (ABC), do grupo Disney, que, por sua vez, em 1996, passou a controlar totalmente a WTN, disposta 2019. 
a ocupar o lugar de maior provedor de notícias para emissoras internacionais. Em 1992, a Reuters incorporou de vez ao seu portfólio de holdings a Visnews, comprando as ações remanescentes da BBC e NBC.

A AP oficializou seu braço audiovisual em 1994, adotando uma estratégia de marketing segundo a qual estaria mais isenta de "influências" externas: aparecia no cenário como uma empresa "puramente voltada" à atividade jornalística, avessa às fusões, desatrelada das grandes corporações e emissoras (caso da WTN), e cujo único negócio era mesmo "vender" notícias. Essa descrição particularmente se contrapunha à imagem da maior concorrente, a Reuters TV, cujos produtos de mídia representavam apenas de $5 \%$ a $10 \%$ do faturamento do grupo empresarial de inteligência informativa ${ }^{2}$. Em 1998, quatro anos depois de inaugurar suas primeiras instalações, a APTV comprou $80 \%$ das ações da ABC da WTN (ex-UPITN) por 55 milhões de dólares, tornando-se APTN.

Nesse cenário, a rede americana CBS nunca estabeleceu vínculos acionários com as agências de televisão como as rivais NBC e ABC. Todavia, comportava-se como força paralela, não somente pela dimensão ocupada dentro dos Estados Unidos, mas, essencialmente, porque desde a década de 1970 também atuava como distribuidora de suas reportagens para emissoras (“CBS-I”), bem como cedia sua infraestrutura para operações no exterior.

Apesar de as agências terem sido inicialmente concebidas na Europa como propriedades privadas, governos logo se envolveram no gerenciamento e/ou funcionamento das transmissões de notícias, acessando, controlando e pulverizando um volume informativo bilateral (o que saía e entrava), disseminando ideias e, acima de tudo, projetando uma imagem positiva no exterior. Isso se deu por uma infinidade de mecanismos jurídicos que incluíam desde a propriedade direta das agências até financiamentos de canais seguros de comunicação, subsídios e concessão de tarifas. Por meio da construção de uma agência transnacional que operava em parceria com as "quatro grandes", os governos se posicionavam enquanto Estados. Em certa medida, hoje os canais de notícia 24 horas reproduzem esses papéis, ao aspirarem a um status internacional para promover os interesses locais da "nação" (BOYD-BARRETT, 2002b; BOYD-BARRETT, 2010; SHRISVASTAVA, 2007).

\footnotetext{
2 Formado por uma série de holdings que ofereciam desde transações financeiras, serviços de consultoria jurídica e impostos, até produtos informativos e gerenciais nas áreas de saúde e ciência.
}

Revista Pauta Geral-Estudos em Jornalismo, Ponta Grossa, vol. 6, n. 1, p. 78-94, Jan/Jun, 2019. 
Tunstall e Palmer (1991) comparam o trabalho dos primeiros correspondentes das agências ao de um diplomata, administrando conflitos internos em nome de interesses externos, e vice-versa; transitando em ciclos militares, políticos e comerciais, fossem eles radicais, progressivos ou moderados, e furando a concorrência e os jornais por meio da troca de favores. Prue Torney-Parlicki (2000) lembra que os cinegrafistas da então Visnews tinham passe livre para circular em regimes fechados, como Coreia do Norte e China. Na tentativa de desatrelar seus serviços à da agenda estatal, as agências promulgaram em seus princípios independência, liberdade e exatidão e trataram de colocar, debaixo do tapete, seu papel histórico de produzir desinformação patriótica nas guerras. Nos anos 1990, a diplomacia soft se desloca sem da esfera das agências para se firmar nos terrenos dos canais por cabo e satélite, como a CNNI, que assume, com a o potencial tecnológico dos satélites, uma suposta mediação crítica e imparcial do relato internacional, evidentemente contestada ( BOYD-BARRETT, 2010; THUSSU, 2006).

Agências anglo-americanas e europeias construíram um simulacro de modelo jornalístico tolerado por clientes (jornais) com interesses, idiomas e zonas de tempo diferenciados. A objetividade emergiu, assim, como um recurso material, cultural e econômico. Coube às agências fazer relatos informativos sobre o que aconteceu, sem ocupar-se com contextos e análises interpretativas além da clássica equação da notícia (Quem? O quê? Quando? Como? Onde? Por quê?).

O correspondente do jornal ou da emissora se encarregaria da reportagem, escapando de padrões, ouvindo vozes múltiplas, reelaborando contextos, enquanto as agências seguiriam reproduzindo somente fontes "críveis", em geral, autoridades. Mesmo quando submetidas à pressão industrial, logística, política e comercial (os interesses dos maiores clientes, os governos, o tempo, os recursos), as agências, como fontes para conglomerados midiáticos, repousaram seus princípios em transparência e neutralidade por meio de seus processos seletivos. Os manuais das agências inclusive deixam claro que o cliente precisa saber se a viagem até a zona de guerra foi viabilizada por unidades de exército ou se o vídeo foi cedido por organizações não governamentais ou, ainda, disponibilizados por fontes anônimas da internet. Foi por meio dessas estratégias discursivas que as agências consolidaram o brand que seus textos são despidos de um "viés ideológico". Por fim, cristalizou-se a ideia de que cada cliente seria responsável pela acomodação do conteúdo, adaptando-o aos seus interesses.

Revista Pauta Geral-Estudos em Jornalismo, Ponta Grossa, vol. 6, n. 1, p. 78-94, Jan/Jun, 2019. 


\section{A narrativa russa}

Depois de sair vitorioso das urnas e voltar ao Kremlin em 2010, Vladimir Putin reconquistou sua popularidade prometendo uma "Rússia" que sobreviveu aos ataques constantes de um Ocidente decadente. Pouco a pouco, nas palavras de Daria Litvinova (2018), "Putin foi construindo um poder vertical, um sistema em que o poder político é centralizado e acumulado por Moscou, com outros atores se reportando ao Kremlin ou sendo controlados por ele". O pilar midiático erguido por Putin também fez parte dessa guinada para uma espécie de reprogramação da identidade russa. O fato é que, segundo Litivinova, $86 \%$ dos russos ainda se alimentam das notícias do mundo pela televisão, cuja rede é dominada por canais estatais ${ }^{3}$.

O canal 24 horas Russia Today (Rossiya Segodnya) foi lançado em 2005, projetando-seo como uma espécie de versão russa da "BBC", com objetivo de ajudar no desmante do estereótipo russo no mundo e, por conseguinte, a percepção do Ocidente de que o país era sinônimo de muito frio, comunismo e pobreza (ibid). Em 2013, um decreto presidencial (legal) transformou a agência Ria Novosti em outra instituição, com um novo foco: promover as políticas russas no mundo. A desculpa oficial era buscar economia de despesas. A agência se fundiu com a emissora de rádio Golos Rossii. Todavia, como relata a autora do artigo, a Ria Novosti gerava negócios e tinha custo reduzido, se comparado à emissora VGTRK, também controlada pelo governo.

É um processo nebuloso que até hoje o establishment russo evitou se explicar. "Nós nos tornamos muito autossustentáveis e independentes? Nós despertamos a ira do Kremlin por cobrir extensivamente os protestos de 2011 e 2012?", questiona Litvinova (ibid.). No ano seguinte, uma lei aprovada proibiu que estrangeiros criassem empresas de mídia no país. A legislação também limita a participação a participação de outros países nas ações das empresas russas.

Em abril de 2013, a Ruptly foi inaugurada à luz desse contexto, com objetivo de contemplar e atrair um maior número de clientes. Não seriam apenas as emissoras de outros países ou os serviços de 24 horas de notícias em canais a cabo. Havia, sobretudo, um projeto ambicioso: vender vídeos para sites, blogues e canais na internet nanicos, que jamais poderiam arcar com os custos de uma assinatura como a Reuters TV ou APTN, ou nem mesmo as outras duas que disputam o mercado, a francesa AFPTV e os serviços da

3 Sobre as questões da RT e outras mídias como instrumentos da máquina de propaganda russa, veja também DOWLING (2017), ERLANGER (2017), RUTENBERG (2017).

Revista Pauta Geral-Estudos em Jornalismo, Ponta Grossa, vol. 6, n. 1, p. 78-94, Jan/Jun, 2019. 
espanhola EFETV. A Ruptly chegou com uma agenda clara: abandonar cláusulas rígidas de contratos, barateá-los e dissipar temários que colidiriam com o critério de noticiabilidade das concorrentes.

Um ano depois de se estabelecer num dos lugares mais caros de Berlim, um editorial da revista alemã Spiegel Online (SPIEGEL STAFF, 2014) descrevia a Ruptly como um tímido plano pra tentar se contrapor à Reuters e AP, enquanto a RT, apenas 9 anos depois de ser criada, já tinha ultrapassado a rede internacional americana CNN quando se comparava vídeos compartilhados no YouTube, perdendo apenas para BBC, com 1.2 bilhões de visualizações. "O Kremlin investe 100 milhões de euros por ano nos veículos de comunicação russos para influenciar a opinião pública do Ocidente" (ibid.).

O aparecimento da Rutply gerou desconfiança no mercado, tanto para quem consome direta ou indiretamente (público), para quem usa e compra seus serviços (jornalistas e/ou empresários). As agências formaram seus nichos. Há quase um consenso nas redações de que a EFE e AFP se saem bem nas coberturas latinoamericanas; em alguns casos, como nos Estados Unidos, a AP está no patamar à altura da Reuters, aquela que funciona como uma referência para redatores e editores impossibilitados de apurar com seus próprios recursos. A Reuters tem um capital simbólico de credibilidade em todos os assuntos e regiões.

A pergunta é: haveria, então, mais um espaço a reivindicar?

Já argumentamos (ESPERIDIÃO, 2011) que seria inviável cobrir o mundo sem essas quatro empresas europeias e americanas, diante do desmantelamento dos escritórios de correspondentes no mundo todo. Apesar do dado ter sido levantado há 8 anos, uma assinatura anual de uma agência custava no mínimo 20 mil dólares. Mas, em média, para grandes emissoras, os contratos passavam de 200 mil. Falava-se de até 2 milhões. Com o sangramento das empresas jornalísticas em escala global e local, muitas empresas reduziram os serviços de assinatura. Raramente, no escopo dos orçamentos atuais, uma única emissora alocaria seu aporte em quatro agências simultaneamente, visto que seus informes, identificados como "feeds", são similares em se tratando de "breaking news", "ongoing story" ou qualquer acontecimento não previsto.

No entanto, por ter sido pensada para servir num ambiente absolutamente digital, a Ruptly introduziu um novo modelo de assinatura, que custa apenas 12,50 euros por mês. Claro que o valor não se aplica às emissoras de grande porte, com audiência na casa de milhões, já que os contratos se baseiam na audiência e no escopo dos clientes e no tipo

Revista Pauta Geral-Estudos em Jornalismo, Ponta Grossa, vol. 6, n. 1, p. 78-94, Jan/Jun, 2019. 
de serviço prestado. A assessoria de imprensa da Ruptly resumiu assim a estratégia: "É um modelo desenhado para pequenos sites. Com este tipo de cabeça, um modo alternativo de olhar o mercado se tornou necessário para melhor entender o que os clientes precisam". ${ }^{4}$ E continua:

\begin{abstract}
A Ruptly é uma agência nascida na ambiência digital. O que significa que, a partir do momento da concepção, sempre claramente considerou as mudanças na era digital e suas demandas nas rotinas produtivas de notícias, além dos desafios que emissoras e plataformas online enfrentam. Acima de tudo, como uma típica "start-up", a Ruptly conseguiu trazer agilidade às decisões diárias do que é notícia, experimentando formas mais avançadas de prospectar informações e, ao mesmo tempo, considerando o desejo atual do cliente (ibid).
\end{abstract}

Há também uma estratégia de apresentar-se com um diferencial inovador diante dos concorrentes. Na mesma entrevista, a agência declara que foi "a primeira a enviar drones para zonas de guerra como a Síria e a Ucrânia e lançando vídeos de 360 graus que podem ser distribuídos em literalmente três cliques direto para as redes sociais dos clientes" (ibid). Síria, Ucrânia e Venezuela são, aliás, zonas de influência política Russa e há sempre um vasto material a respeito desses países na plataforma da Ruptly que, a princípio, parece reproduzir a mesma arquitetura online das outras agências, como se seguirão os prints no final deste artigo.

No entanto, enquanto Reuters se vende como a que oferece uma "cobertura confiável, não-parcial que aumenta a sua credibilidade" ${ }^{5}$, e a AP evoca seus 170 anos sempre oferecendo um conteúdo "comprometido com os mais altos padrões de objetividade e exatidão"6, a Ruptly se promove assim:

A Ruptly se baseia na força dos valores na família Russia Today. Nossa missão é oferecer uma cobertura mais ousada e profunda do que outras figuras estabelecidas no mercado de notícias. Nós oferecemos uma visão inovadora: notícias, mas sem estarmos de olhos vendados". ${ }^{7}$

\footnotetext{
4 Em entrevista à autora do artigo, por comunicação interna (e-mail). Por determinação da Ruptly, as respostas devem estar nomeadas como Assessoria de Imprensa da Ruptly (Press Room).

5 "Accurate, timely and unbiased coverage adds to your credibility". Disponível em: <https://agency.reuters.com/en/about-us.html> Acesso em 12 de fevereiro de 2019.

6 "Always committed to the high standards of objective, accurate journalism". Disponivel em: <https://www.ap.org/about/>. Acesso em 12 de fevereiro de 2019

7 "Our mission is to offer a bolder, deeper point-of-view than the established figures of the news marketplace. We offer a forward-thinking vision, news without the blindfold on"

Revista Pauta Geral-Estudos em Jornalismo, Ponta Grossa, vol. 6, n. 1, p. 78-94, Jan/Jun, 2019.
} 
A Russia Today não esconde em seus alicerces o seu projeto de ter como "princípio estabelecer uma nova maneira de engajar a audiência para questionar mais, em destacar assuntos não cobertos pela mídia tradicional, trazendo uma perspectiva alternativa sobre os temas atuais, sob a miríade Russa acerca dos grandes eventos mundiais"8. E virou o centro de um grande debate depois dos escândalos associados à interferência russa nas eleições americanas e no Brexit (TALMAZAN, 2016).

Em tese, a Ruptly oferece coberturas simétricas sobre os temas, inclusive não se furtando a mostrar opositores de Putin, mesmo aqueles encarcerados e demonizados. Pela nossa experiência como editora, nas coberturas da Venezuela, a agência obedeceu aos padrões típicos de agência, ao escutar os polos políticos e seus adversários, oferecendo vídeos com entrevistas de opositores e chavistas. No entanto, seria necessário avaliar com cuidado os vídeos e os informes pra fazer qualquer ilação no sentido de comparar os conteúdos.

É fato que, em coberturas de acessos restritivo às agências e com carta branca para Moscou (ação militar americana à Síria e ajuda humanitária à Venezuela), os serviços de transmissões ao vivo da Ruptly foram mais presentes e ágeis, desbancando todas as concorrentes, e com o maior número de vídeos gravados por celulares. Cinco anos atrás, no editorial da revista alemã que já citamos, as críticas à Rutply já eram claras:

Num primeiro momento, não é óbvio que a Ruptly é realmente uma TV do Kremlin. Além dos discursos de Putin, é possível achar nos arquivos vídeos numerosos, desde a banda Pussy Riot até a prisão de opositores. Mas, quando avaliamos o leste da Ucrânia, a agência oferece quase que exclusivamente vídeos favoráveis aos que são apoiados por Moscou, além de entrevistas com partidos de extrema direita, que odeiam a União Europeia e as políticas públicas ucranianas (SPIEGEL STAFF, 2014).

"Sempre temos um pé atrás com os conteúdos escritos, usamos mais as imagens do que as informações ajuntadas pela agência", disse-nos um jornalista que vêm

Disponível em: <https://video.ruptly.tv/\#/en/about-ruptly>. Acesso em 12 de fevereiro de 2019.

8 Nossa tradução para: "RT creates news with an edge for viewers who want to Question More. RT covers stories overlooked by the mainstream media, provides alternative perspectives on current affairs, and acquaints international audiences with a Russian viewpoint on major global events. Disponível em: https://www.rt.com/about-us. Acesso em 03 de fevereiro de 2019.

Revista Pauta Geral-Estudos em Jornalismo, Ponta Grossa, vol. 6, n. 1, p. 78-94, Jan/Jun, 2019. 
observando o crescimento da Ruptly". "Não é algo para levar a sério, pois o conteúdo é contaminado", declarou, também de forma anônima, um dos funcionários de uma concorrente.

Questionamos se o governo Russo dita mesmo as regras do conteúdo da Ruptly, se o objetivo é tornar invisíveis os oponentes políticos de Moscou, liquidar vozes plurais e restringir a liberdade dos seus jornalistas. Mas essas acusações foram negadas pela empresa:

Nunca negamos o fato de sermos parte do grupo RT. Mas dizer que o governo russo controla nosso trabalho é completamente falso. Nós temos independência editorial de empresa para empresa, e nosso critério é formado nos interesses e nas demandas dos nossos clientes e futuros clientes. Nossas decisões editoriais são coletivas, feitas pela nossa equipe, formada por jornalistas de mais de 35 países $^{9}$.

\section{Como fica o atual ecossistema noticioso do telejornalismo internacional}

Como APTN e Reuters escolheram sua sede em Londres, Berlim foi a opção da Ruptly para a troca de conteúdos e disparo dos informes. A justificativa é que a capital alemã tem uma combinação de vantagens que vão desde instalações mais baratas à tradição da presença russa na cidade. A figura a seguir tenta apresentar como fica a irrigação do sistema noticioso global, com a presença das cinco agências citadas neste artigo:

Figura 1: Rede de provedores de imagens para a mídia mundial, de acordo com nossa perspectiva

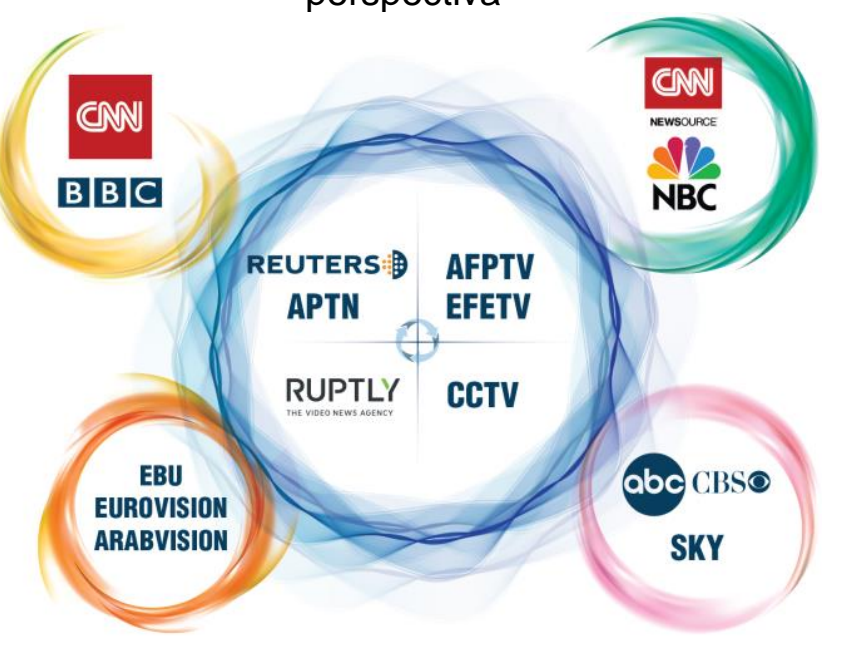

\footnotetext{
9 Em entrevista à autora do artigo por comunicação interna (e-mail).
}

Revista Pauta Geral-Estudos em Jornalismo, Ponta Grossa, vol. 6, n. 1, p. 78-94, Jan/Jun, 2019. 
Do lado esquerdo, estão os grandes canais de notícias do mundo (CNN e BBC). Abaixo, também à esquerda, exemplos de consórcios de troca de imagens de três continentes (Eurovision e Arabvision). Do lado direito, o agenciamento de conteúdos das emissoras que é também um serviço de assinatura (Newsource, apresentando os vídeos da CNN; e NBC, com os vídeos de reportagens que foram ao ar na emissora americana NBC). Do lado direito abaixo, emissoras que vendem seus conteúdos em parceria com agências (as americanas ABC e CBS e a britânica Sky News). No centro, incluímos também a chinesa CCTV, controlada pelo governo chinês, cujos conteúdos são muitas vezes distribuídos gratuitamente pela Reuters e APTN.

Figura 2: Números das agências que operam para emissoras de televisão e outros veículos envolvendo vídeos. Números tendem a mudar. Reuters e APTN têm suas sedes em Londres, mas operam grandes hubs nos Estados Unidos e Ásia

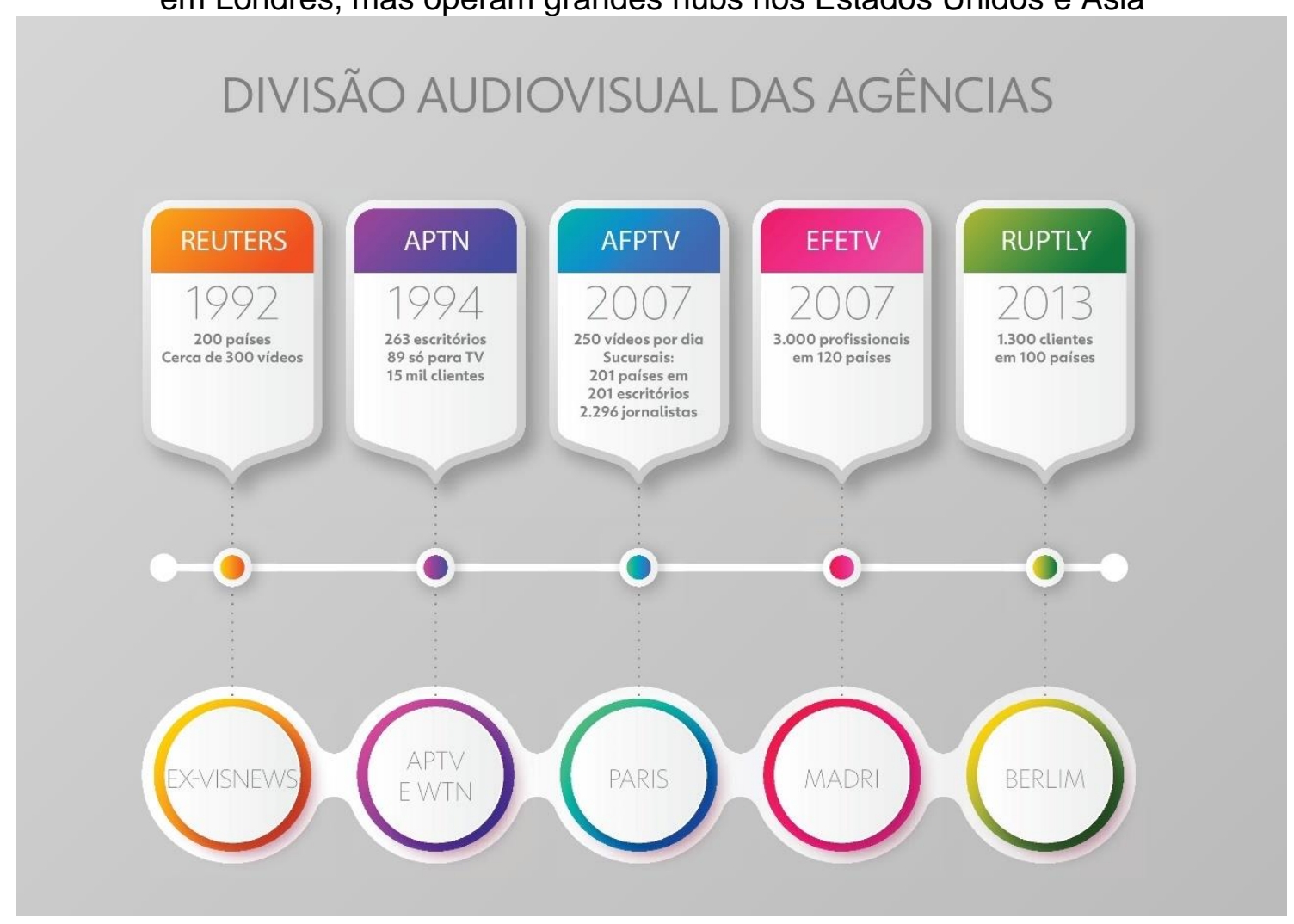

Revista Pauta Geral-Estudos em Jornalismo, Ponta Grossa, vol. 6, n. 1, p. 78-94, Jan/Jun, 2019. 


\section{Conclusões}

O jornal americano The New York Times publicou artigo esmantelando a versão americana de que forças de segurança e pessoas ligadas ao presidente Nicolás Maduro queimaram comida enviada pelos americanos, colombianos e brasileiros ${ }^{10}$. As imagens contradizem essa informação, praticamente reproduzida por todos os telejornais do mundo, com base nas agências de notícias. Seria interessante investigar que abordagens políticas se sobressaíram na cobertura da Ruptly: se mais agudamente para o campo pró ou contra Maduro. Um trabalho de campo em seus escritórios talvez elucidasse como a tribo jornalística da agência se comporta diante de pressões. O que acreditamos é que a Ruptly nunca teve como objetivo se colocar na retórica de um "ângulo justo dos fatos", como se ainda fosse possível ainda aceitar uma neutralidade em todas as etapas da construção da notícia nas agências ocidentais. A questão crucial aqui é que tipo de benefício jornalistas e a sociedade têm a ganhar com a busca por um protagonismo fora das empresas dominantes.

Figura 3: Print da plataforma da agência Ruply, com destaque da Venezuela

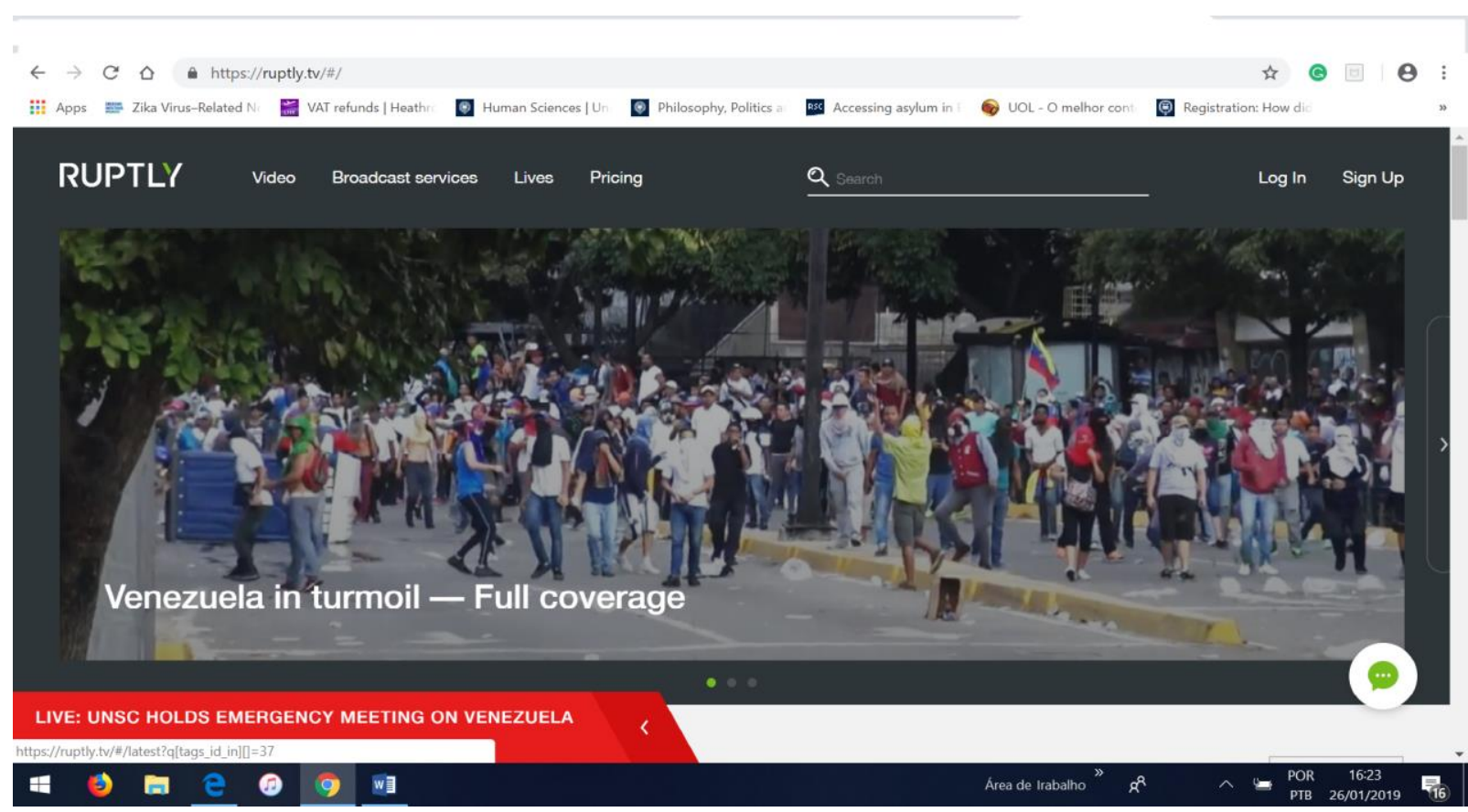

10 Disponível em: <https://www.nytimes.com/2019/03/10/world/americas/venezuela-aidfire-video.html>, aceso em 10 de março de 2019.

Revista Pauta Geral-Estudos em Jornalismo, Ponta Grossa, vol. 6, n. 1, p. 78-94, Jan/Jun, 2019. 


\section{ESTUDOS EM JORNALISMO}

10.5212/RevistaPautaGeral.v6.i1.0005

Figura 4: Ofertas de coberturas ao vivo e já transmitidas na plataforma da Reuters:

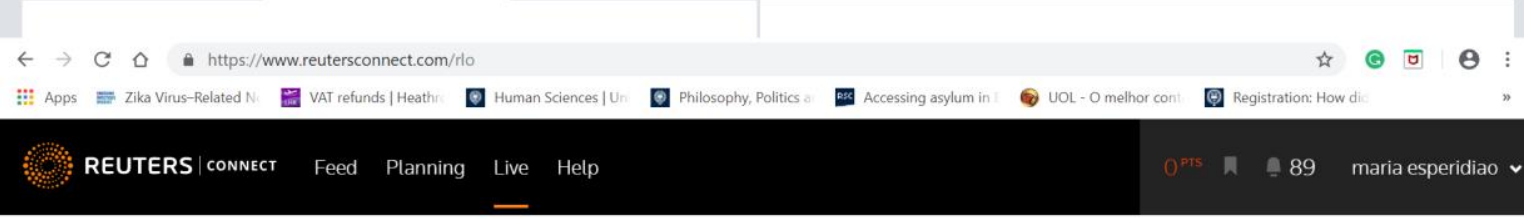

冓 r rood $<$ Saturday, January 26th

$: \equiv 24$ hrs $=\#$ Now

\begin{tabular}{|c|c|c|c|}
\hline STATUS & SLUG & START & END \\
\hline D. live & $\begin{array}{l}\text { VENEZUELA.POUTICS/UN - } \\
\text { UPDATED DETAILS- }\end{array}$ & $11: 47$ & TBD \\
\hline Tlive & $\begin{array}{l}\text { FRANCE- } \\
\text { PROTESTS/YELLOWNIGHT - } \\
\text {-UPATTED DETAILS - }\end{array}$ & $13: 13$ & TBD \\
\hline Q) scheduled & $\begin{array}{l}\text { POPE-YOUTH/VIGIL-- } \\
\text { UPDATED START TIME- }\end{array}$ & $21: 30$ & TBD \\
\hline T) scheduled & $\begin{array}{l}\text { FRANCE- } \\
\text { PROTESTS/CASTANER - } \\
\text { TIMING TBC- }\end{array}$ & TBD & TBD \\
\hline Tompleted & $\begin{array}{l}\text { VENEZUELAN- } \\
\text { POLITICS/OPPOSITION }\end{array}$ & $13: 41$ & 15:01 \\
\hline (2) completed & POPE-YOUTH/MASS & 12:34 & $14: 37$ \\
\hline (1) completed & $\begin{array}{l}\text { FRANCE-PROTESTS/ - } \\
\text { UPDATED DEIAllS - }\end{array}$ & 09:17 & 10:20 \\
\hline
\end{tabular}

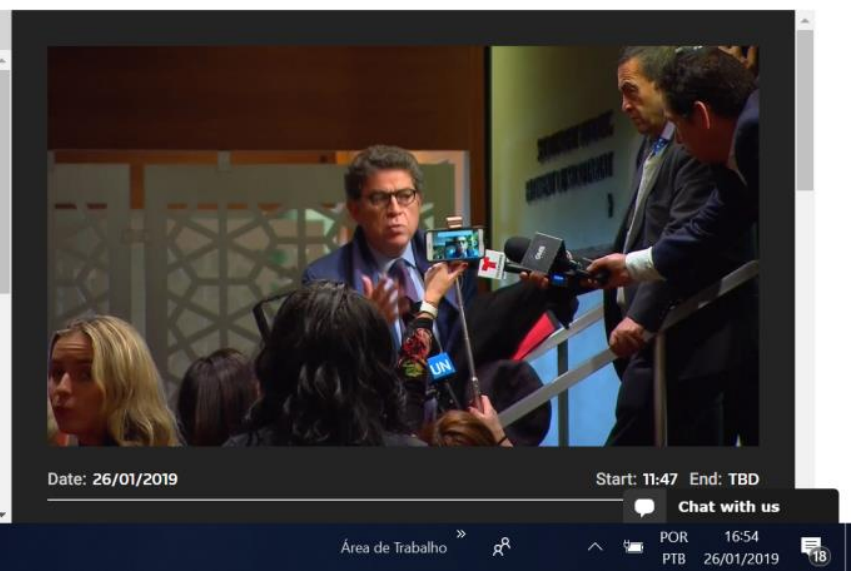

Figura 5: Outro template da Ruptly

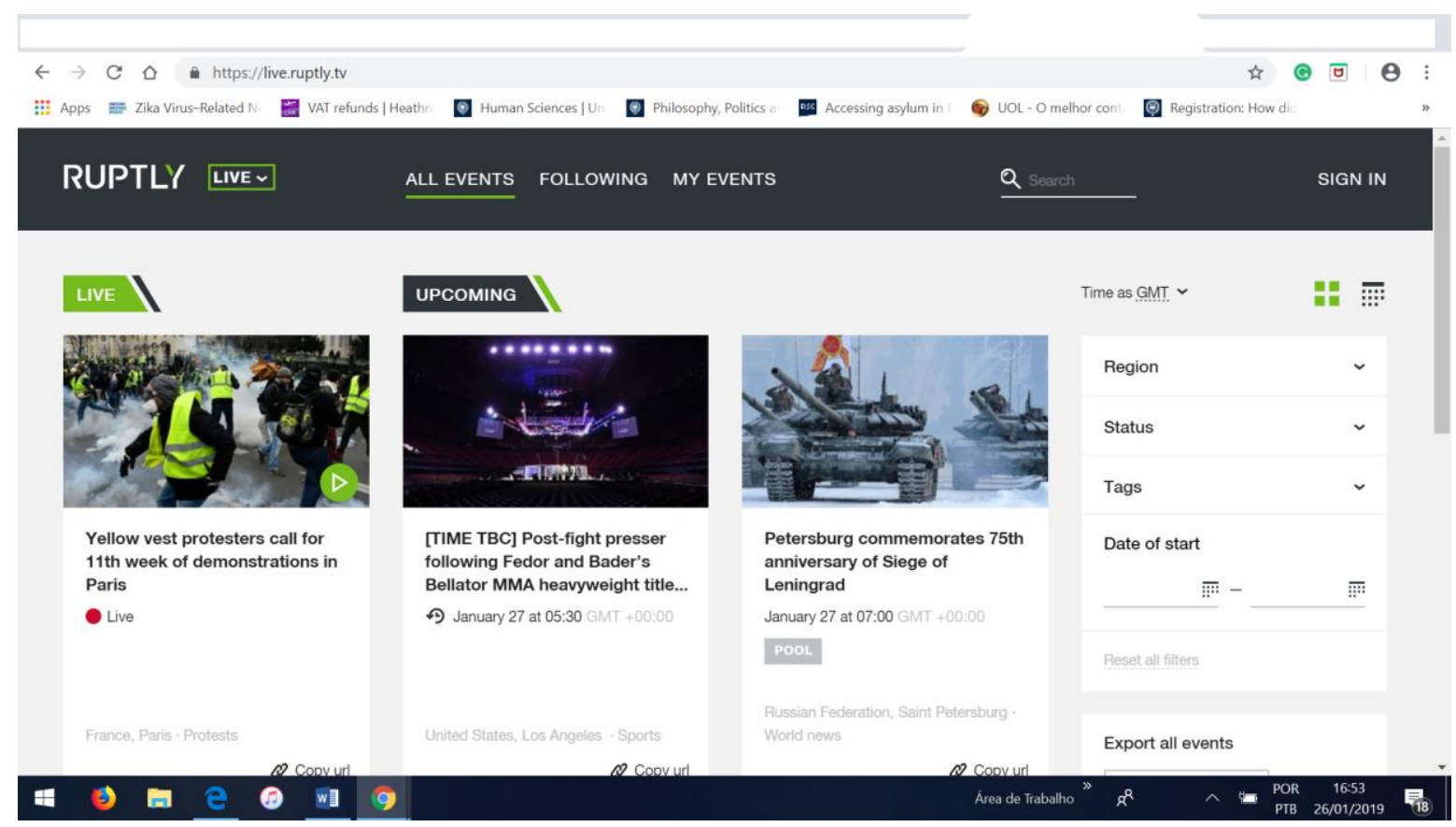

Figura 6: Plataforma da APTN de vídeos ao vivo

Revista Pauta Geral-Estudos em Jornalismo, Ponta Grossa, vol. 6, n. 1, p. 78-94, Jan/Jun, 2019. 


\section{ESTUDOS EM JORNALISMO}

10.5212/RevistaPautaGeral.v6.i1.0005

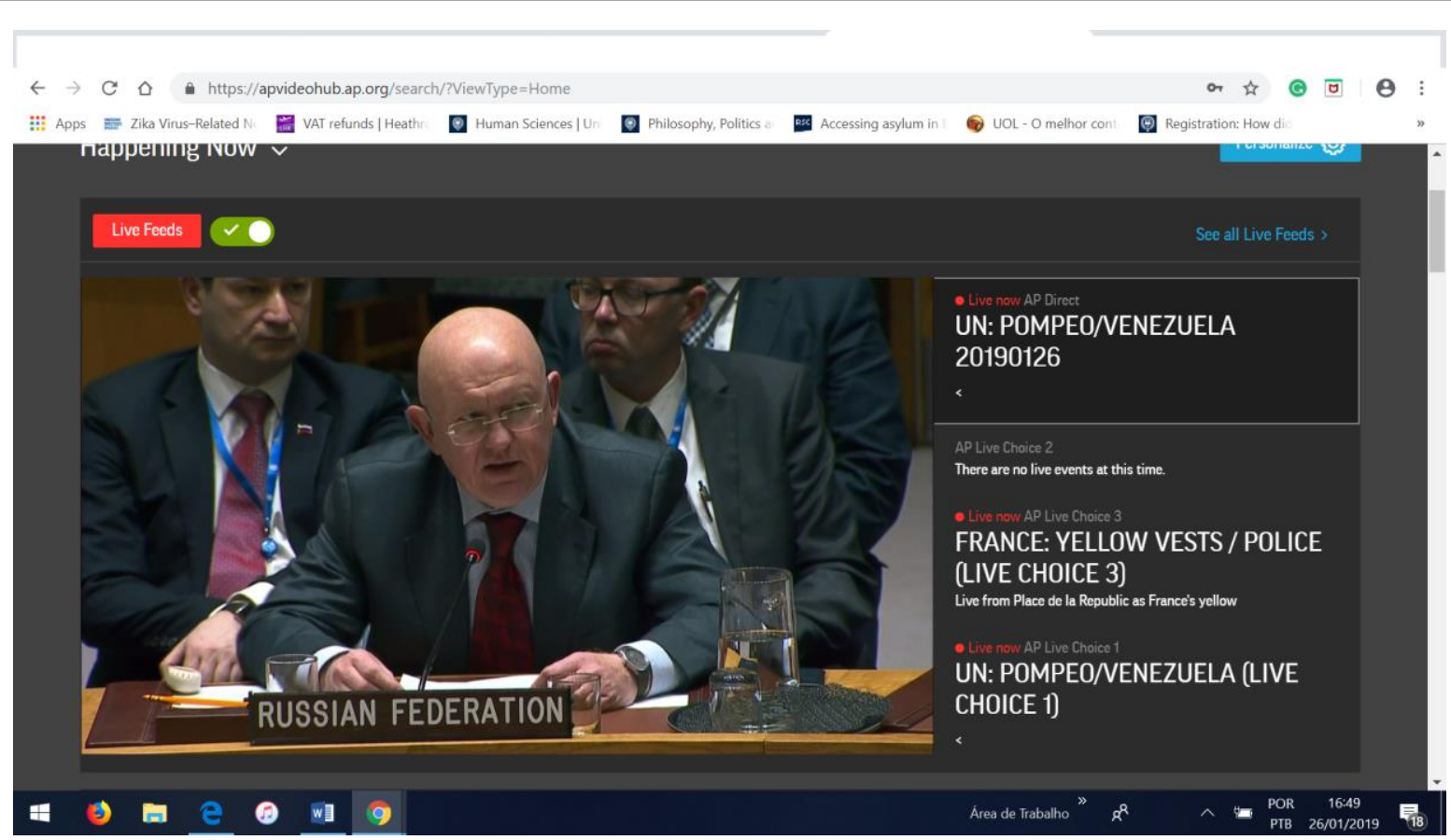

Figura 7: Plataforma da chinesa CCTV

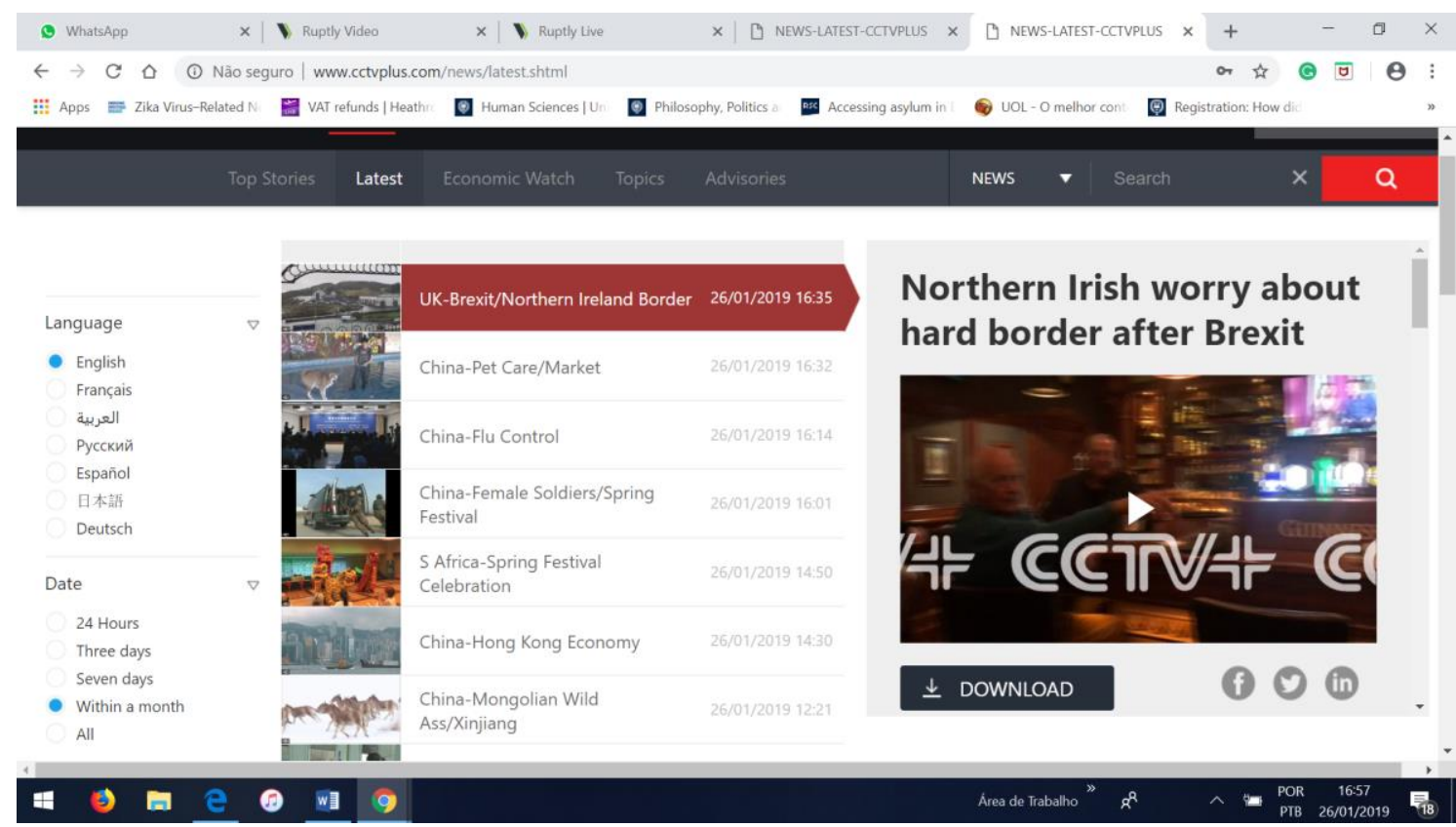

Figura 8: Plataforma da EFETV para clientes que testam seus serviços

Revista Pauta Geral-Estudos em Jornalismo, Ponta Grossa, vol. 6, n. 1, p. 78-94, Jan/Jun, 2019. 


\section{ESTUDOS EM JORNALISMO}

10.5212/RevistaPautaGeral.v6.i1.0005

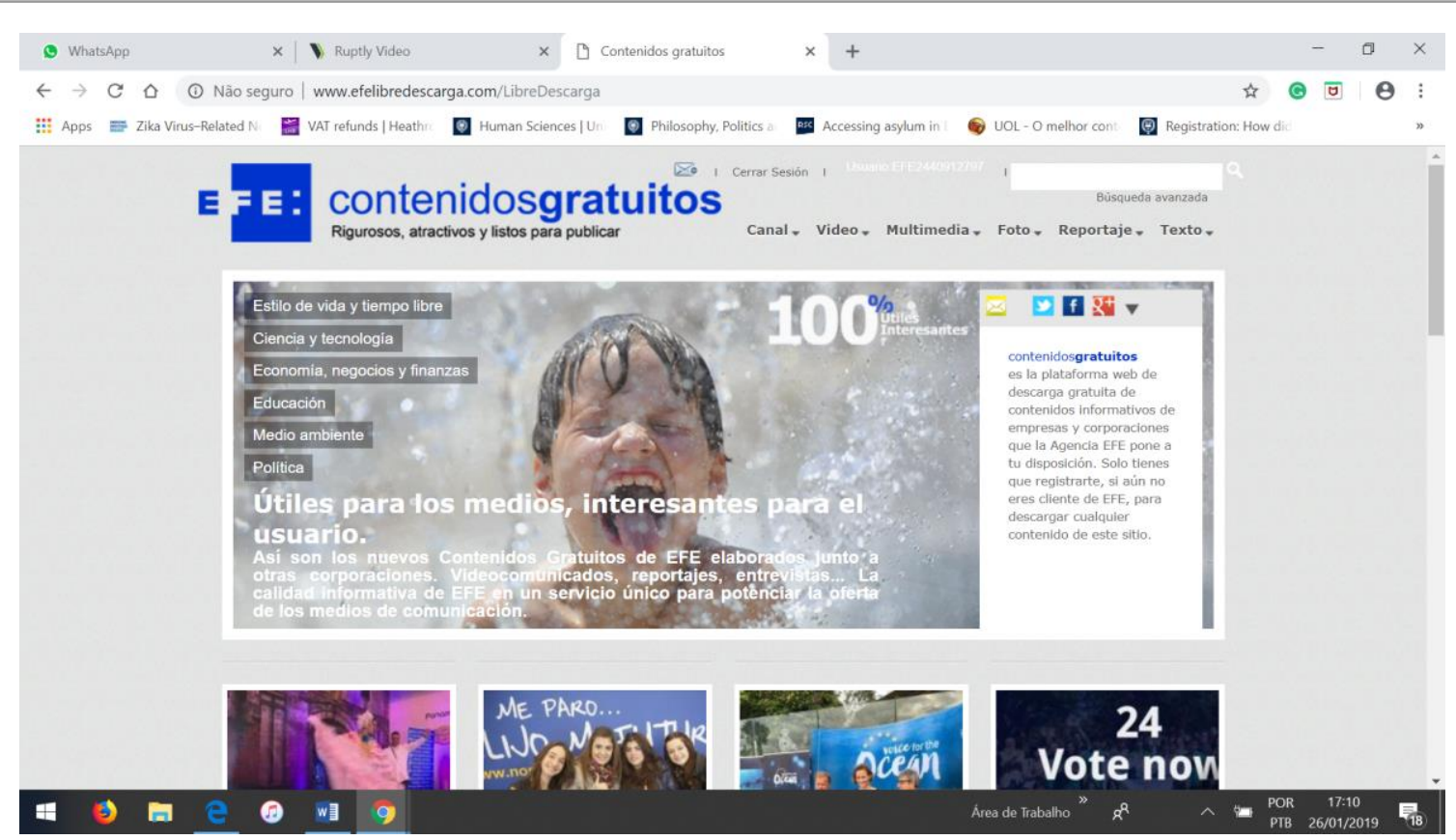

Figura 09: Plataforma ao vivo da AFPTV

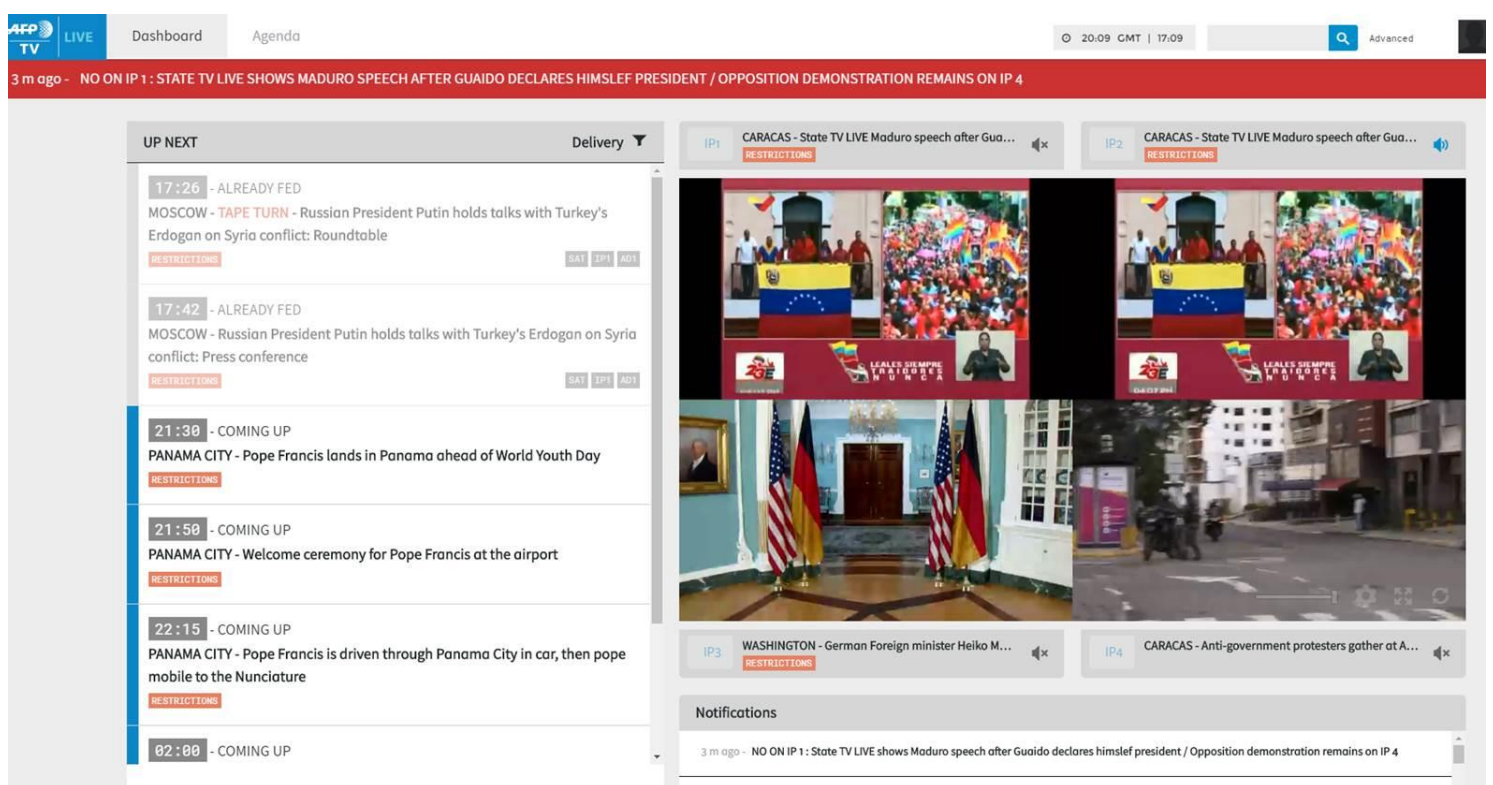

Revista Pauta Geral-Estudos em Jornalismo, Ponta Grossa, vol. 6, n. 1, p. 78-94, Jan/Jun, 2019. 


\section{ESTUDOS EM JORNALISMO}

Figura 10: Plataforma da americana NBC

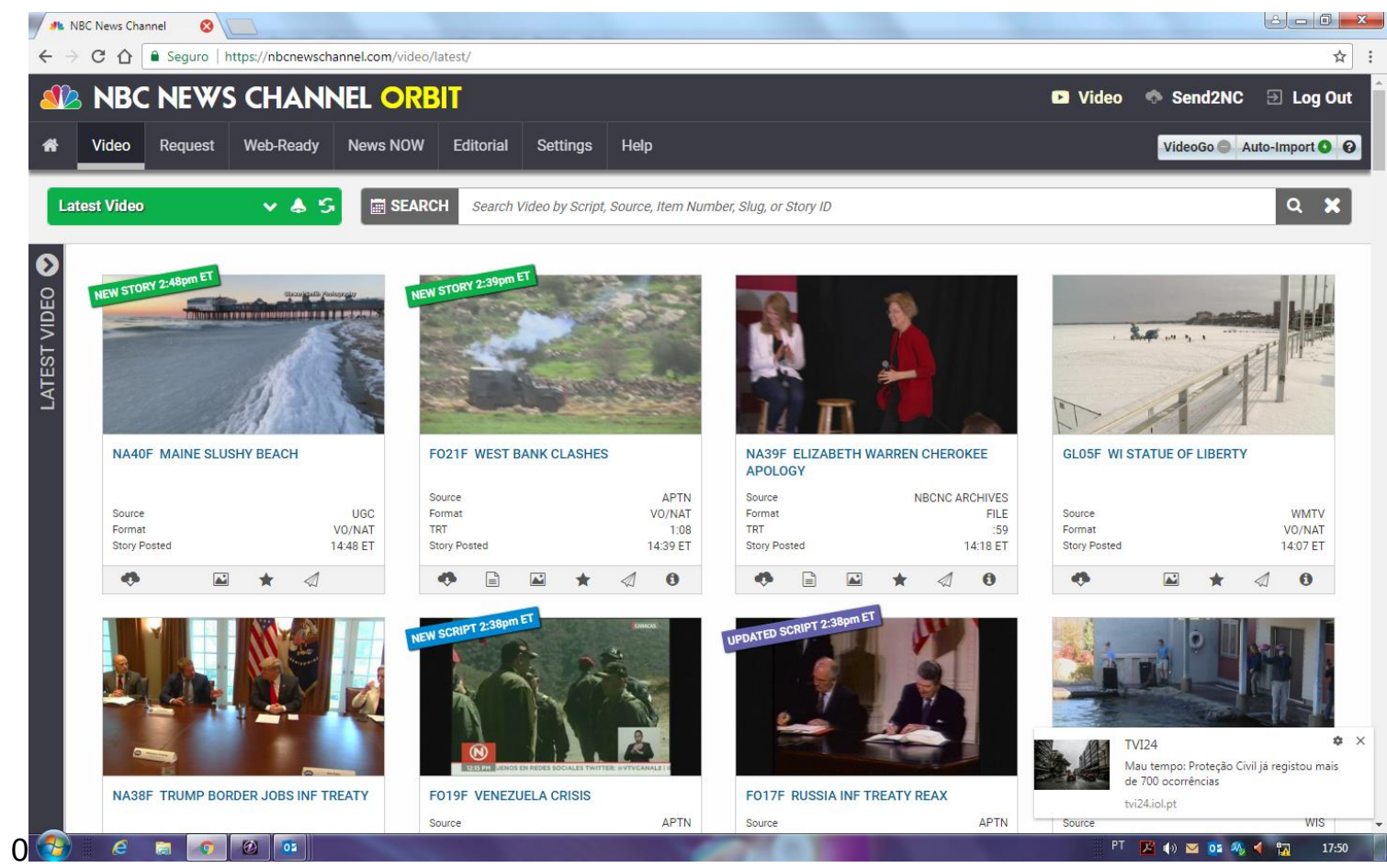

\section{Referências}

BOYD-BARRETT, Oliver (2010). National news agencies in the turbulent era of the internet. Barcelona: Government of Catalonia, 2010.

. Towards the "new model" news agency. In: AUSTRIA PRESS AGENTUR (Ed.). The various faces of reality: values in news (agency) journalism. Vienna: Studien Verlag, 2002b. p. 91-96.

CASTELLS, Manuel. A sociedade em rede. 8. ed. São Paulo: Paz e Terra, 2005.

DOWLING, T (2017) "24-hour Putin people: my week watching Kremlin 'propaganda channel' RT". Disponível em: <https://www.theguardian.com/media/2017/nov/29/24-hourputin-people-my-week-watching-kremlin-propaganda-channel-rt-russia-today $>$. Acesso em 7 de março de 2019.

ERLANGER, S (2017). "What is RT?". Disponível em:

https://www.nytimes.com/2017/03/08/world/europe/what-is-rt.html. Acesso: 7 de fevereiro de 2019. Versão em português, publicada pela Folha de São Paulo:

<https://www1.folha.uol.com.br/mundo/2017/03/1865017-emissora-russa-rt-e-agenciasde-noticias-ou-propaganda-do-kremlin.shtml>. Acesso em 6 de março de 2019 
ESPERIDIÃO, Maria Cleidejane. Gigantes invisíveis no telejornalismo mundial: agências internacionais de notícias e o ecossistema noticioso global. Brazilian Journalism Review, v.7, n.1, 2011.

LITVINOVA, D. (2018). Human wrongs: how-stated backed media helped the kremilin weaponise social conservatism. Disponível em:

$<$ https://reutersinstitute.politics.ox.ac.uk/our-research/human-wrongs-how-state-backedmedia-helped-kremlin-weaponise-social-conservatism>. Acesso em 15 de janeiro de 2019.

PATERSON, C. The international television news agencies: the world from London. Nova York: Peter Lang (2011).

RUTENBERG, J. (2017). RT, Sputnik and Russia's new theory of war. Disponível em: <https://www.nytimes.com/2017/09/13/magazine/rt-sputnik-and-russias-new-theory-ofwar.html>. Acesso em 20 de fevereiro de 2019.

SILVA JR., José Afonso. ESPERIDIÃO, Maria Cleidejane. AGUIAR, Pedro (orgs). Agências de Notícias: perspectivas contemporâneas. Recife: EdUFPE, 2014.

SHRIVASTAVA, K.M. News agencies: from pigeon to internet. Nova Délhi: New Dawn Press, 2006.

SPIEGEL STAFF (2014). How Russia is winning the propaganda war. Disponível em: <http://www.spiegel.de/international/world/russia-uses-state-television-to-sway-opinion-athome-and-abroad-a-971971.html>. Acessado em 20 de fevereiro de 2019.

TALMAZAN, Y at all (2017). Don't be afraid of Russia, head of 'propaganda outlet' RT says. Disponível em: <https://www.euronews.com/2017/12/30/u-s-needn-t-fear-russia-rteditor-chief-margarita-n831736>. Acesso em 06 de março de 2019.

TORNEY-PARLICKI, Prue Somewhere in Asia: war, journalism, and Australia's neighbours. Sidney: University of South Wales, 2000.

THUSSU, Daya Kishan (2006). International communication: continuity and change. 2. ed. London: Hodder Arnold, 2006.

TUNSTALL, Jeremy; PALMER, Michael. Media moguls. London: Routledge, 1991.

Recebido em: 10/01/2019.

Publicado em: 23/07/2019. 